\title{
Challenges and particularities in the management of severe bacterial infections in HIV-infected injecting drug users
}

\author{
Irina lanache ${ }^{1}$, Cristiana Oprea ${ }^{1,2}$ \\ 1"Victor Babes" Hospital for Infectious and Tropical Diseases, Bucharest, Romania \\ 2"Carol Davila" University of Medicine and Pharmacy, Bucharest, Romania
}

\begin{abstract}
Injecting drug use became during last decade a major health public issue, both in Romania and around the world. Incidence of HIV and viral hepatitis in injecting drug users (IDUs) has dramatically increased due to the appearance of new highly addictive drugs (called "ethnobotanicals") with unknown effects and associated with increased use of unsterile injecting equipment. Severe bacterial infections with poor outcome often complicate the clinical evolution of these patients, especially in case of severe immunosuppression secondary to HIV.

We will describe in this review the most common bacterial infections developed due to injecting drug use. Bacterial endocarditis in IDUs are usually right-sided, Staphylococcus aureus being the most common pathogen. These patients also develop skin/soft tissues and respiratory tract infections (due to altered local defense mechanisms), as well as sexually transmitted diseases due to high risk sexual behavior, usually determined by recreational drug use. This behavior is known as "ChemSEX" and is usually practiced by men having sex with men. There were also reported cases of wound botulism, tetanus and even anthrax epidemics among IDUs.

HIV infected IDUs usually require complex management with multidisciplinary approach and sometimes surgical treatment.
\end{abstract}

Keywords: intravenous drug users, HIV infection, severe bacterial infections, ChemSEX

\section{General information about injecting drug use in Europe and in Romania}

Even if there are multiple ways of using drugs, intravenous administration has became a particular issue worldwide during the last decade, being an important challenge for authorities due to its economic, social and legal implications. The most important are the medical implications, both directly, due to overdoses and indirect through infections with intravenous transmission (1).

In contrast to other ways of drug use (smoking, inhalation or ingestion), injecting drug use is associated with more rapid absorption and metabolism of the substances, as well as crossing of the bloodbrain barrier and the highly addictive effect (2).
It is estimated that there are 13 million IDUs around the world, the number being variable from one region to another. Almost $10 \%$ of them are HIV infected and $67 \%$ have HCV antibody positive, while more than 1.1 million IDUs are $\mathrm{HIV} / \mathrm{HCV}$ co-infected (3).

Opioids and drugs like cocaine, amphetamines or psycho-stimulant substances are the most common injected drugs in Europe (4). However, it seems that the prevalence of injecting use of heroin has decreased from $43 \%$ in 2006 to $33 \%$ in 2014 , with important differences from one country to another (ranging from $11 \%$ to $90 \%$ ) (4). An important increase of injecting psycho-stimulant substances was observed in the last years, associated with an 
alarming increase in the number of newly HIV-infected IDUs (at least 3 times higher comparing to non-injecting users of the same drugs), due to the use of unsterile injecting equipment and high risk sexual behaviors (5). Compared to opioids, psychostimulant drugs have a shorter half-life time, requiring multiple injections per day, associating a high risk of needle and syringes sharing, and as a consequence, a higher risk of infections (6). In addition, IDUs have often high risk behavior, having multiple partners and unprotected sexual intercourses with occasional partners, which is the case also in MSM (men having sex with men) patients (5).

Both Romania and Greece have raised attention regarding injecting drug use in 2011 when the increased number of HIV cases was reported among IDUs from this region (4). Only a few cases of HIV infection were reported in Romania among patients from vulnerable groups between 2007 and 2010 (incidence variable between $1 \%$ and $3 \%$ ). An alarming increase of HIV-infected IDUs was reported since 2011, with an ascending trend until 2013 and a maximum incidence of $30 \%$ reported in 2012. However, a descending trend was reported in the following years, with a decrease in incidence to $16 \%$ in 2016 (7). These changes in the pattern of drug use, with high accessibility for psycho-stimulant drugs, locally known as "ethnobotanicals", associated with reduced access to harm-reduction programs were responsible for this evolution, with an ascending trend until 2013 - 2014 (8). The number of ethnobotanical drugs users and HIV incidence in these patients were significantly reduced when these substances have become illegal and the "dream" stores were closed (9).

Ethnobotanical drugs are synthetic cathinones derived from Catha edulis plant, with effects similar to other drugs like cocaine, MDMA or ecstasy. In addition to the amphetamine-like stimulant effects, a high number of IDUs considered these drugs safer and started using them trying to avoid heroin addiction. Due to their short half-life time, ethnobotanical drugs require multiple injections per day $(6-10)$, a therefore an increased risk of unsterile injecting equipment use and needle sharing, and as a consequence, a higher rate of transmission of parenteral infections. A high number of opioid addicts tried to switch from heroin and use ethnobotanical drugs, but ended up by being addicted to both of them (10-12).

\section{Severe bacterial infections in IDUs}

HIV-infected patients often develop opportunistic infections and severe bacterial infections due to immunosuppression secondary to HIV, tuberculosis (TB) being the most common cause of death in these patients (13).

Even if almost all infections and complications diagnosed in IDUs were frequent also before the spread of HIV among patients with high risk behaviors, it seems that their incidence has increased dramatically in the context of immunosuppression secondary to HIV, being associated with more complications and poor outcome.

Risk factors like sharing unsterile injecting equipment, poor oral hygiene, alcohol consumption, smoking or commercial sex are considered to be responsible for the high frequency of severe bacterial infections in IDUs. In addition, these patients are great carriers of microorganisms on their skin and mucosa and they often have altered cough or sneeze reflexes leading to high frequency of aspiration. Moreover IDUs have usually poor access to health care services, with low rate of screening for HIV and hepatitis. (14).

\section{Infective endocarditis (IE)}

Clinical suspicion of bacterial endocarditis is thought to be one of the most frequent causes of hospital admissions in intravenous drug users. The risk of endocarditis is considered to be correlated with the duration of injecting drug use. The incidence of endocarditis in IDUs is estimated to be around $2-5 \%$ and is most often diagnosed in young males, with a median age between 20 and 30 yearold. The mortality rate is considered to be $5-10 \%$ (14-16).

Even if the incidence, morbidity rate and recurrence of endocarditis are high in HIV infected patients, it seems that the mortality rate is most often influenced by the pathogen responsible for the cardiac damage and the affected valve and not by HIV itself (14). However, the mortality rate is higher in patients with CD4 cell count lower than 200 cells/ $\mathrm{mm}^{3}$, or with concomitant AIDS defining diseases $(15,17)$. 
Injecting drug use leads to cardiac damage through a variety of mechanisms. It is a known fact that the injected solutions contain materials (talcum), which can affect the cardiac valves. In addition, due to poor hygiene, injecting drug use favors high bacterial loads to arrive in the blood stream and then to the endocardium. Drugs with short halflife time (eg. cocaine or ethnobotanicals) require multiple administrations per day, determining the increase of bacterial loads in the blood and as a consequence, increased risk of endocarditis (15, 16).

Even if fever of unknown etiology in an HIVinfected injecting drug user raises a high index of suspicion of infectious endocarditis, this diagnosis needs to be confirmed, because fever is an unspecific symptom associated with a high number of diseases, including a hyper sensibility reaction to the injectable drugs $(14,16)$.

IDUs often develop right sided endocarditis, with lack of systemic signs and symptoms. Heroin is considered to increase the pulmonary arterial pressure, associated with high levels of turbulence in the tricuspid valve and a high risk of damage (14-16). In addition, due to the intravenous drug administration, the right-sided valves are the first ones that have contact with the blood containing the injected materials, most often the tricuspid valve $(15,16)$. There are reported cases of mitral or aortic valve involvement and even of concomitant right and left-sided valve lesions (16). Thus, cocaine and methamphetamine-like substances increase cardiac return with a high risk of turbulence at the aortic or mitral valves and damages of these structures. Under these circumstances, the type of cardiac disease can sometimes be suggested by the type of the injecting drug used (18-20).

Patients with tricuspid valve endocarditis have usually positive blood cultures $(16,19)$. Staphylococcus aureus is the microorganism most often responsible for infectious endocarditis, especially Methicillin-sensitive Staphylococcus aureus (MSSA). Methicillin-resistant Staphylococcus aureus (MRSA), streptococcus, gram negative bacilli, fungi and HACEK microorganisms (Haemophilus species, Actinobacillus actinomycetemcomitans, Cardiobacterium hominis, Eikenella corrodens, Kingella kingae) were rarely reported, while Pseudomonas aeruginosa was associated with concomitant multi- ple valve involvement $(14-16,19)$. Bartonella spp has to be considered as a possible etiology in case of right-sided endocarditis with negative cultures (16).

It is estimated that right-sided endocarditis with staphylococcal etiology are associated with favorable outcome in IDUs and with low mortality rate $(14,19)$. In contrast, left-sided endocarditis, with other etiology than MSSA are usually associated with poor outcome, high risk of complications and high mortality rates. Both the level of valve damage and the congestive heart failure secondary to infectious endocarditis play a significant role in the outcome of the disease in IDUs. The high risk of septic emboli with systemic dissemination (especially in the brain), as well as multiple organ failure, are risk factors for a high mortality rate in these patients. Taking into consideration that a damaged valve has a greater risk to be damaged compared to a native one, IDUs have also a higher risk of recurrences because of the ongoing drug use. Therefore, broad-spectrum antibiotic treatment and surgical interventions are essential for these patients (14, $16,19)$.

\section{Skin and soft tissues infections}

Injecting drug users have frequent presentation to medical services requiring treatment for skin and soft tissues infections. These complications are caused by pathogens that are present on the skin, by inoculation in the wound through unsterile intravenous, intramuscular or subcutaneous injections. The spectrum of infections varies from uncomplicated diseases like cellulites or abscesses, to erysipelas and phlegmons to life-threatening conditions such as septic thrombophlebitis or necrotizing fasciitis $(14,21,22)$.

IDUs have often a chronic damage of the skin and the vascular system in the context of repeated injections with scar formation, wounds, edema or adenopathy. Under these circumstances, diagnosis of skin infections and adequate treatment are often delayed because they can be neglected for a long period of time.

The classical signs of local inflammation with increased local temperature, hyperemia, edema and pain with or without fever shouldn't be neglected in intravenous drug user patients. The presence of bacteremia highlights the severity of infection, sug- 
gesting empyema or endovascular involvement $(14,23)$. Pathogens usually responsible for these conditions are those residual on the skin, group A beta hemolytic streptococcus or other streptococcus, as well as Staphylococcus aureus being most often isolated, with increasing incidence of MRSA during last time $(14,23)$.

Necrotizing fasciitis, myositis and septic thrombophlebitis are life threatening conditions, being considered medical and surgical emergencies. Even if associated with low frequency, these infections shouldn't be neglected and the presence of skin cramps represents an alarming sign. They usually associate etiology with multiple pathogens, Gram negative and Gram positive bacteria, both aerobes and anaerobes. Therapeutic management implies intensive broad-spectrum parenteral antibiotic treatment and surgical intervention with drainage and debridement of devitalized tissues and necroses (14).

Skin ulcers usually appear as granulomatous inflammation and necrosis; they associate a high risk of superinfection and are often diagnosed in female patients who inject drugs subcutaneously. There were also described cases of septic thrombophlebitis occurring due to unsterile injection which required surgical treatment with venous ligation (14).

Injecting drug use was also associated with skin and soft tissue infections with spore forming bacteria, like Clostridium or Bacillus spp. as etiology. Thus, there were reported cases of wound botulism, tetanus and even anthrax. Even if very rare, they are considered to be very severe cases of sepsis with starting point on the skin, due to the intravenous drug administration (14,21,24,25).

Countries like Norway, Germany or Great Britain reported cases of wound botulism starting with 2013. The heroin contaminated with Clostridium botulinum spores was considered to be responsible for these infections, while Bacillus cereus was the pathogen identified in IDUs who used amphetamines and developed skin infections in Norway at the beginning of 2016 (26).

Anthrax in intravenous drug users was reported for the first time in Norway in 2000. Later, two epidemics were reported: between 2009 and 2010 in Scotland, England and Germany, and between 2012 and 2013 in Great Britain, France, Denmark and Germany respectively. The source of infection wasn't identified, but heroin contaminated with spores and injected subcutaneously or directly in the soft tissues is considered to be responsible for these infections $(21,24,27,28)$.

They usually associate severe clinical evolution and a high risk of complications, like cellulites or necrotizing fasciitis. Under these circumstances, the correct diagnosis and early initiation of correct treatment are essential for the favorable evolution of these patients $(24,28)$. Management of such infections requires antibiotic treatment and immunoglobulin administration, as well as surgical interventions. However, the mortality rate is estimated to be $30 \%(21,29)$.

\section{Respiratory tract infections}

Injecting drug users are estimated to associate a ten times higher risk of upper respiratory tract infections comparing to general population. Local defense mechanisms, like mucociliary clearance or macrophage activity, are altered in the context of smoking or illicit drug use. In addition, opioid substances have the potential to alter the cough and sneezing reflex and contribute to disturbing the body's defense mechanisms (30).

HIV-infected IDUs also associate a high risk of pneumonia and sepsis, which is estimated to be 4-5 times higher comparing to IDUs without HIV, especially in case of severe immunosuppression, with a CD4 cell count below 350 cells $/ \mathrm{mm}^{3}$.

Pathogens considered to be responsible for community-acquired pneumonia are the same as in general population: Streptococcus pneumoniae, Staphylococcus aureus, Haemophilus influensae i Klebsiella pneumoniae (14). In addition, IDUs frequently develop aspiration pneumonia and are more vulnerable to influenza due to poor general health state (30).

Some authors tried to identify a possible link between the drugs used and the predominant pulmonary affection. Thus, in addition to the altered cough and sneeze reflexes, narcotic drugs can also diminish the consciousness, favoring the development of aspiration pneumonia and lung abscesses. However, injected methamphetamines were not connected to any respiratory tract infections (30).

\section{Sexually transmitted infections}

Both injecting and non-injecting drug users often associate sexually transmitted infections (STIs), 
with high risk in the context of commercial sex practiced in order to obtain drugs, or due to their high risk sexual behavior practiced due to drugs effects (30).

Among non-injectable drugs, the crack (smoking cocaine) is most often associated with STIs, due to the increased incidence of high risk sexual behavior as well as the users awareness of STIs $(30,31)$. The incidence of STIs significantly increased during last decade due to the high use of recreational drugs among patients from vulnerable groups, drugs known as "CHEMS" or "club/party drugs". The importance of this problem is greater taking into consideration that their use is often associated with high risk sexual behavior, increased rate of unsterile injecting equipment and a high awareness of HIV and other STIs risk of transmission. These drugs are often used by young HIV positive men, in clubs, parties or during other social events (32-34).

The use of drugs for sex is known as "ChemSEX", the most common drugs used being mephedrone, crystal methaphetamine and GBH/GBL. Mephedrone is related to cathinone's substances, with structure similar to amphetamine and MDMA. It is usually sold as "bath salts" or "food plants" and it is known for its effects: euphoria, increased concentration, alertness and mild sexual stimulation. Similarly, crystal methaphetamine is associated with increased euphoric state, energy, impulsivity, lowered inhibitions, increased tolerance to pain and intense sexual stimulation. GBH/GBL (Gammahydroxybutyrate/Gammabutyrolactone) is an important central nervous system depressant due to its role in blocking the central receptors for $\gamma$-aminobutyric acid (GABA), one of the most important central inhibitors (35-38).
ChemSEX implies intense long term sexual disinhibition and multiple sexual intercourses with multiple partners. Recreational drug users often adopt such behavior in order to overcome their inferiority complexes and problems from the past including sexual abuses, to avoid the fear of rejection, sexual shame or the loneliness. They also want to feel part of a community, to connect with others, or just because "everyone is doing it" - "ChemSEX culture" (32-34).

Recreational drugs and ChemSEX are now a major public health issue, especially for MSM communities from West European countries (3537, 39, 40).

Syphilis, gonorrhea and infections with Chlamydia or Trychomonas vaginalis are the most common STIs diagnosed in IDUs $(30,41)$. More than that, the high incidence of Herpes Simplex 2 infection (HSV-2) in IDUs highlights the high risk of HIV transmission through sexual contacts in vulnerable groups $(41,42)$.

Management of HIV-infected IDUs is a huge challenge for the health care systems with important clinical, social and economic involvement. In the context of immunosuppression secondary to HIV, these patients often develop both opportunistic infections and severe bacterial infections which are frequently considered medical and surgical emergencies, with clinical particularities and poor outcome. Therefore, knowing the pattern of bacterial infections associated to injecting drug use and the pathogens frequently responsible for these infections may be an important tool in the fight to reduce morbidity and mortality in patients from vulnerable groups.

Conflict of interest: none declared Financial support: none declared

\section{REFERENCES}

1. Evans J.L., Tsui J.I., Hahn J.A., Davidson P.J., Lum P.J., Page K. Mortality among young injection drug users in San Francisco: a 10-year follow-up of the UFO study. American journal of epidemiology. 2012; 175(4):302-8.

2. European Monitoring Centre for Drugs and Drug Addiction (EMCDDA). Trends in Injecting Drug Use in Europe 2010 [cited 2017 July]. Available from: www.emcdda.europa.eu/printpdf/publications/ selected-issues/injecting_en.

3. World Health Organisation (WHO). Consolidated Guidelines on HIV prevention, diagnosis, treatment and care for key populations 2016 [cited 2017 July]. Available from: http://apps.who.int/iris/bitstre am/10665/128048/1/9789241507431_eng.pdf?ua=1\&ua=1 .

4. Observatorul European privinf Drogurile. Raportul national privind drogurile - Tendinte si evolutii 20162016 [cited 2017 September 2017]. Available from: http://www.emcdda.europa.eu/system/files/ publications/2637/TDAT16001RON.pdf.

5. Tavitian-Exley I., Vickerman P., Bastos F.I., Boily M.C. Influence of different drugs on HIV risk in people who inject: systematic review and meta-analysis. Addiction. 2015; 110(4):572-84.

6. Van Hout M.C., Bingham T. "A costly turn on": patterns of use and perceived consequences of mephedrone based head shop products amongst Irish injectors. The International journal on drug policy. 2012; 23(3):188-97. 
7. Comisia Nationala de Lupta anti-SIDA (CNLAS). Evolutia infectiei HIV/SIDA in Romania 31 Decembrie 20162016 [cited 2017 July]. Available from: http://www.cnlas.ro/images/doc/31122016_rom.pdf.

8. United Nations Office on Drugs and Crime (UNODC). Global SMART Update Volume 15: Special Segment: Injecting use of synthetic drugs 2016 [cited 2017 July]. Available from: https://www.unodc.org/ documents/scientific/Global_SMART_Update_Vol.15_web.pdf.

9. European Monitoring Centre for Drugs and Drug Addiction (EMCDDA). Romania country overview 2016 [cited 2017 July]. Available from: http://www.emcdda.europa.eu/publications/ country-drug-reports/2017/romania_en.

10. 1European Monitoring Centre for Drugs and Drug Addiction (EMCDDA).;Agentia Nationala anti-Drog. Raportul national privind situatia drogurilor 2016; Romania - noi tendinte si evolutii 2016 [cited 2017 July]. Available from: http://www.ana.gov.ro/rapoarte\%20 nationale/RN_2016.pdf.

11. Karila L., Megarbane B., Cottencin O., Lejoyeux M. Synthetic cathinones: a new public health problem. Current neuropharmacology. 2015; 13(1):12-20.

12. Karila L., Megarbane B., Chevillard L., Benturquia N., Laplanche J.L., Lejoyeux M. [Novel psychoactive substances: a review]. Presse medicale. 2015; 44(4 Pt 1):383-91.

13. Pawlowski A., Jansson M., Skold M., Rottenberg M.E., Kallenius G. Tuberculosis and HIV co-infection. PLOS pathogens. 2012; 8(2):e1002464.

14. Bruce R.D., Altice F.L. Clinical care of the HIV-infected drug user. Infectious disease clinics of North America. 2007; 21(1):149-79, ix.

15. Melinyte K., Savickaite J., Rekiene D.E., Naudziunas A., Burkauskiene A., Jankauskiene L. Infective endocarditis in an HIV-infected intravenous drug user. Revista portuguesa de cardiologia : orgao oficial da Sociedade Portuguesa de Cardiologia = Portuguese journal of cardiology : an official journal of the Portuguese Society of Cardiology. 2015; 34(10):619 e1-5.

16. Weymann A., Borst T., Popov A.F., Sabashnikov A., Bowles C., Schmack B. et al. Surgical treatment of infective endocarditis in active intravenous drug users: a justified procedure? Journal of cardiothoracic surgery. 2014; 9:58.

17. Bartlett J.G. Endocarditis - injection drug users: Johns Hopkins ABX Guide; [cited 2017 July]. Available from: https://www.hopkinsguides. com/hopkins/view/Johns_Hopkins_ABX_Guide/540192/all/ Endocarditis_ injection_drug_users.

18. Cooper H.L., Brady J.E., Ciccarone D., Tempalski B., Gostnell K., Friedman S.R. Nationwide increase in the number of hospitalizations for illicit injection drug use-related infective endocarditis. Clinical infectious diseases: an official publication of the Infectious Diseases Society of America. 2007; 45(9):1200-3.

19. Ji Y., Kujtan L., Kershner D. Acute endocarditis in intravenous drug users: a case report and literature review. Journal of community hospital internal medicine perspectives. 2012; 2(1).

20. Jain V., Yang M.H., Kovacicova-Lezcano G., Juhle L.S., Bolger A.F., Winston L.G. Infective endocarditis in an urban medical center: association of individual drugs with valvular involvement. The Journal of infection. 2008;57(2):132-8.

21. Grunow R., Verbeek L., Jacob D., Holzmann T., Birkenfeld G., Wiens D. et al. Injection anthrax--a new outbreak in heroin users. Deutsches Arzteblatt international. 2012; 109(49):843-8.

22. Fink B., Landthaler M., Hafner C. Hautveränderungen durch Missbrauch illegaler Drogen. JDDG: Journal der Deutschen Dermatologischen Gesellschaft. 2011;9(8):633-40.

23. Crum N.F., Lee R.U., Thornton S.A., Stine O.C., Wallace M.R., Barrozo C. et al. Fifteen-year study of the changing epidemiology of methicillin-resistant Staphylococcus aureus. The American journal of medicine. 2006; 119(11):943-51.

24. Ascough S., Altmann D.M. Anthrax in injecting drug users: the need for increased vigilance in the clinic. Expert review of anti-infective therapy. 2015; 13(6):681-4.

25. Palmateer N.E., Ramsay C.N., Browning L., Goldberg D.J., Hutchinson S.J. Anthrax Infection Among Heroin Users in Scotland During 2009-2010: A Case-Control Study by Linkage to a National Drug Treatment Database. Clinical Infectious Diseases. 2012; 55(5):706-10.
26. European Monitoring Centre for Drugs and Drug Addiction (EMCDDA). Drug-related infectious diseases in Europe; Update from the EMCDDA expert network Luxemburg: Office of the European Union; 2016 [cited 2017 July]. Available from: http://www.emcdda. europa.eu/system/files/publications/3393/TD0416796ENN.pdf.

27. Ramsay C.N., Stirling A., Smith J., Hawkins G., Brooks T., Hood J. et al. An outbreak of infection with Bacillus anthracis in injecting drug users in Scotland. Euro surveillance : bulletin Europeen sur les maladies transmissibles $=$ European communicable disease bulletin. 2010; 15(2).

28. Berger T., Kassirer M., Aran A.A. Injectional anthrax - new presentation of an old disease. Euro surveillance : bulletin Europeen sur les maladies transmissibles $=$ European communicable disease bulletin. 2014; 19(32).

29. Grunow R., Grunow D., Schaade L. Anthrax - serologische Untersuchung zur Fallfindung von Bacillus-anthracis-Expositionen bei Heroinkonsu-menten in Deutschland im Zeitraum 2010-2011; Robert Koch-Institut. Epidemiologisches Bulletin. 2012; 26.

30. European Monitoring Centre for Drugs and Drug Addiction (EMCDDA). Guidelines for testing HIV, viral hepatitis and other infections in injecting drug users Lisabon: EMCDDA Manuals; 2010 [cited 2017 July]. Available from: http://www.emcdda.europa.eu/ publications/manuals/testing-guidelines_en.

31. van den Hoek A. STD control in drug users and street youth. Genitourinary medicine. 1997; 73(4):240-4.

32. Bracchi M., Stuart D., Castles R., Khoo S., Back D., Boffito M. Increasing use of 'party drugs' in people living with HIV on antiretrovirals: a concern for patient safety. AIDS. 2015; 29(13):1585-92.

33. Bourne A., Reid D., Hickson F., Torres-Rueda S., Weatherburn P. Illicit drug use in sexual settings ('chemsex') and HIV/STI transmission risk behaviour among gay men in South London: findings from a qualitative study. Sexually transmitted infections. 2015; 91(8):564-8.

34. Hunter L.J., Dargan P.I., Benzie A., White J.A., Wood D.M. Recreational drug use in men who have sex with men (MSM) attending UK sexual health services is significantly higher than in non-MSM. Postgraduate medical journal. 2014; 90(1061):133-8.

35. Peyrière H., Jacquet J.M., Eiden C., Tuaillon E., Psomas C., Reynes J. Viral and bacterial risks associated with mephedrone abuse in HIV-infected men who have sex with men. AIDS. 2013; 27(18):2971-2.

36. Brennan R., Van Hout M.C. Gamma-hydroxybutyrate (GHB): a scoping review of pharmacology, toxicology, motives for use, and user groups. Journal of psychoactive drugs. 2014; 46(3):243-51.

37. Ottaway Z., Finnerty F., Amlani A., Pinto-Sander N., Szanyi J., Richardson D. Men who have sex with men diagnosed with a sexually transmitted infection are significantly more likely to engage in sexualised drug use. International journal of STD \& AIDS. 2017; 28(1):91-3.

38. Giorgetti R., Tagliabracci A., Schifano F., Zaami S., Marinelli E., Busardo F.P. When "Chems" Meet Sex: A Rising Phenomenon Called "ChemSex". Current neuropharmacology. 2017; 15(5):762-70.

39. Gilbart V.L., Simms I., Jenkins C., Furegato M., Gobin M., Oliver I., et al. Sex, drugs and smart phone applications: findings from semistructured interviews with men who have sex with men diagnosed with Shigella flexneri 3a in England and Wales. Sexually transmitted infections. 2015; 91(8):598-602.

40. Daskalopoulou M., Rodger A., Phillips A.N., Sherr L., Speakman A., Collins S. et al. Recreational drug use, polydrug use, and sexual behaviour in HIV-diagnosed men who have sex with men in the UK: results from the cross-sectional ASTRA study. The Lancet HIV.1(1):e22-e31.

41. Khan M.R., Berger A., Hemberg J., O'Neill A., Dyer T.P., Smyrk K. Non-injection and injection drug use and STI/HIV risk in the United States: the degree to which sexual risk behaviors versus sex with an STI-infected partner account for infection transmission among drug users. AIDS and behavior. 2013;17(3):1185-94.

42. Des Jarlais D.C., Arasteh K., McKnight C., Hagan H., Perlman D., Friedman S.R. Using hepatitis $C$ virus and herpes simplex virus-2 to track HIV among injecting drug users in New York City. Drug and alcohol dependence. 2009;101(1-2):88-91. 